\title{
IMPACT OF INDIAN DRAMA SERIALS ON BANGLADESHI CULTURE: A QUALITATIVE STUDY BASED ON PERCEIVED SITUATION AND RISK FACTORS IN URBAN SETTING
}

\section{Shaharior Rahman Razu', Noshin Yeasmin², Sheikh Shareeful Islam³}

\section{Abstract}

This study investigates how Indian TV serials are affecting Bangladeshi culture through changes in lifestyle, family and intimate relationship, and forms of art and literature. The qualitative research was conducted on 60 respondents from Khulna and Dhaka city of Bangladesh who were selected through purposive sampling method. Findings suggest that Indian TV serials have a significant impact on the day-to-day life of people living in Bangladesh. It influences the lifestyle of people as they spend a considerable time watching these TV serials. Alongside, the indigenous art, literature, language, customs and rituals are being shaped due to heavy dependency on Indian TV serials. Such inclination raises concern for some potential risks including family conflicts, crime, psychological disorder and even suicide.

Key words: Indian drama serial, culture, lifestyle, impact, risk factors.

\section{Introduction}

Cable television plays a vital role in the subcontinent, especially in India, Pakistan and Bangladesh (Ali, et al, 2014; Yousaf, et al, 2014). In Bangladesh, BTV was the dominant medium of entertainment for an extended twenty-eight years (1964-1992). In 1992, with the entry of satellite channels, BTV lost its monopoly and unfortunately due to these foreign satellite channels gradually people of Bangladesh are losing their Ben-

\footnotetext{
Assistant Professor, Sociology Discipline, Khulna University, Khulna-9208, Bangladesh, E-mail: razusocku@gmail.com, Contact no.:+8801715333500.

2 MSS in Sociology, Sociology Discipline, Khulna University, Khulna-9208, Bangladesh, E-mail: noshin241194@gmail.com, contact no.: +8801729388847

3 Lecturer, Department of English, Northern University of Business and Technology, Khulna, Bangladesh, E-mail: email: sksarif52@gmail.com, Contact no..+8801719483149
} 
gali norms and customs and getting used to the foreign lifestyles which are detrimental to the social norms and values of Bangladesh (Shamsher and Abdullah, 2012). With this entry of cable TV networks, the Indian TV serials have got immense popularity among the female viewers. A significant number of the housewives in Bangladesh are desperate fan of these serials.

Women in Bangladesh are inclined to watching these Indian TV serials as it works as an instrument of pastime as they have very few other sources of entertainment. However, it was seen only as a source of entertainment in early days, but gradually it started influencing the cultural mechanism and started posing threat to the indigenous culture (Juni, et al, 2014). People imitate Indian fashion, mentality e.g. sari, patialashalwar, chori pajama, sleeveless dressing, short shirts, less use of cheddar (veil). Even Indian rituals are being added into our wedding ceremonies like sagai (engagement), haldi, mehendi, sangeet, and the like. A large number of people are seen wearing Indian style of dressing and using Hindi words in common conversation (Qamar, et al, 2012). In this way, now we are facing cultural conflict and identity crisis at a large scale (Ali, et al, 2015; Naseer, et al, 2014; Helal, 2014). These Indian drama serials provoke sexual behavior, instigate pre and extra martial affair, pre-marital sexual relation, nudity, educate criminal activity, rouse eve teasing, and nurture conflict between family and intimate relationship creating social anomalies that is the extinction of the culture and values of Bangladesh (Islam, 2013; Shamsher and Abdullah, 2012). Mother's attention towards their kids has been lessened due to spending a long time on watching television which causes personality disorders in long term (Ruwandeepa, 2011). Even children are attracted to Hindi soaps when they see their family members watching these shows (Salam, 2013). This intense involvement of female viewers may affect the future generation, either positively or negatively (Khanam, et al, 2014).

Acculturation is often a product of globalization and sometimes it turns into 'Cultural Imperialism' (Tomlinson, 2003; Xue, 2008). With technological advancement, the Indian culture has diffused beyond its national boundaries as it shapes the Bengali culture by habituating the Bangladeshi people to Indian language, clothing, food habit, rituals, attitudes and behavior. It is evident that such cultural aggression through media may lead towards violent and aggressive behavior (Huesmann, 2007; Carey, 1993). Besides, aggression is raising concern as it originates anomalies and malpractice in traditional Bengali family and social life. Under such context, this study attempts to understand how Indian drama serials are affecting the indigenous culture of Bangladesh and what potential risk factors it includes.

\section{Methods and Materials}

The present study tries to explore how Indian drama serials put impact on the culture and social system of Bangladesh through a cross-sectional study. A qualitative approach was adopted for this study because it is generally more suitable for gaining significant in-depth knowledge on the subject's individual experiences and feelings through empirical research. We selected two of the major cities of Bangladesh for this study i.e. Dhaka and Khulna City as the field for conducting this research. Dhaka is the capital of Bangladesh and there is a huge cultural diversity among the residents as they come from different areas of Bangladesh. On the other hand, Khulna is a divisional city of south-west region where people inhabit with more or less the same cultural backdrop. As we aimed at observing the cultural impact of Indian serials on people from both the same and different cultural background, we selected these two cities. After selecting those study area, a methodological triangulation of case studies, Key Informant Interviews (KIIs), and Focus Group Discussions (FGDs) was constructed for data collection.

The participants for the case studies were the female viewers of Indian drama serials irrespective of ethnic or religious background. They were aged at least 18 years and reported of spending at least a couple of hours every day for watching Indian Drama 
serials for the last one year or more. We conducted 20 case studies on housewives who were the prime viewers of Indian drama serial and included their husband, mother-inlaw, daughter-in-law and the like in our Key Informant Interviews (KIIs). We also included some media experts and psychiatrists in our KIls to understand the perspective in this regard. Additionally, two Focus Group Discussions (FGDs) were conducted with 20 participants (10 participants in each session) from the two selected cities. As in qualitative studies credibility relies less on sample size rather on the richness of the gathered information and on the analytical abilities of the researcher, we selected this optimum number of samples that was necessary for the study to reach a conclusion. Hence, the participants were chosen through purposive sampling techniques since it is widely used for the identification and selection of information-rich cases related to the issue of interest (Palinkas et al. 2015). As key study instrument, separate interview schedules and check lists for all three modules of data collection were designed. As case studies were the most intensive part of data collection in this study, individual interviews were carried out with the viewers in a number of sessions. The FGDs provided essential information to understand not only what participants think, but also how and why they think in that way. The FGDs were conducted under the supervision of the chief investigator with the assistance of three trained moderators and two note takers. We distributed the respondents of case studies, FGDs and KIIs from both cities equally (see Tab.1).

Table 1: Composition of the Respondents for Case Studies, FGDs and KIIs

\begin{tabular}{|c|c|c|c|c|}
\hline Method & City & Region & $\begin{array}{l}\text { Number of } \\
\text { Participants }\end{array}$ & Total \\
\hline & \multirow{2}{*}{ Dhaka } & Shah Ali Bag, Mirpur-1 & 6 & \multirow{5}{*}{20} \\
\hline & & Mollah Para. Mirpur-2 & 4 & \\
\hline \multirow{4}{*}{$\begin{array}{c}\text { Case } \\
\text { Studies }\end{array}$} & \multirow{3}{*}{ Khulna } & Gollamari Slum Area & 2 & \\
\hline & & Ward no. 24 & 4 & \\
\hline & & Ward no. 26 & 4 & \\
\hline & Dhaka & Shah Ali Bag, Mirpur-1 & 10 & \\
\hline FGDs & Khulna & Ward no. 26 & 10 & 20 \\
\hline \multirow{6}{*}{ KIIs } & \multirow{4}{*}{ Dhaka } & University of Dhaka & 2 & \multirow{6}{*}{20} \\
\hline & & $\begin{array}{c}\text { Bangabandhu Sheikh Mujib } \\
\text { Medical University }\end{array}$ & 2 & \\
\hline & & Baridhara DOHS & 4 & \\
\hline & & Dhaka Medical College & 2 & \\
\hline & Khulna & Ward no. 24 & 6 & \\
\hline & & Ward no. 26 & 4 & \\
\hline
\end{tabular}

Source: Authors' Compilation

All the data for this study were collected through the in-depth face-to-face interviews by dint of interview schedules, checklist, audio records and essential notes. The data collection took four months-from July 2017 to December 2017. The authors analyzed and interpreted findings from the data collected through case studies, FGDs and KIls through the recorded documents for writing the research report afterwards. We acquired both written and verbal consent from the participants in this study following strict ethical standards. The participants were informed that participation in this study is voluntary and the information collected from them will be kept confidential. Besides, we obtained the institutional approval for data collection from the Academic Committee of Sociology Discipline, Khulna University. 


\section{Main Theme of Indian Drama Serials}

As the study is concerned with how Indian TV serials affect Bangladeshi culture, it includes aspects related to the main themes of these dramas, the main victim of these, the way of becoming affected, changes in lifestyle, art and culture, and its threat to indigenous culture. The Hindi drama serials are predominantly family politics based and involve phenomena like, conspiracy, revenge, extra and pre-marital relationships etc (see Fig. 1). Most of the stories are women-centric and evolve around the tale of a women and her life. Like any other imaginary content, these TV serials focus on emotional features more than practical life. The models in the Indian drama serials are presented attractively which can be seen as commoditization of gender in media. They only show the glazing part of the life through which an individual tends to forget woes of personal life for some moments.

Figure 1: Main Theme of Indian Drama Serials

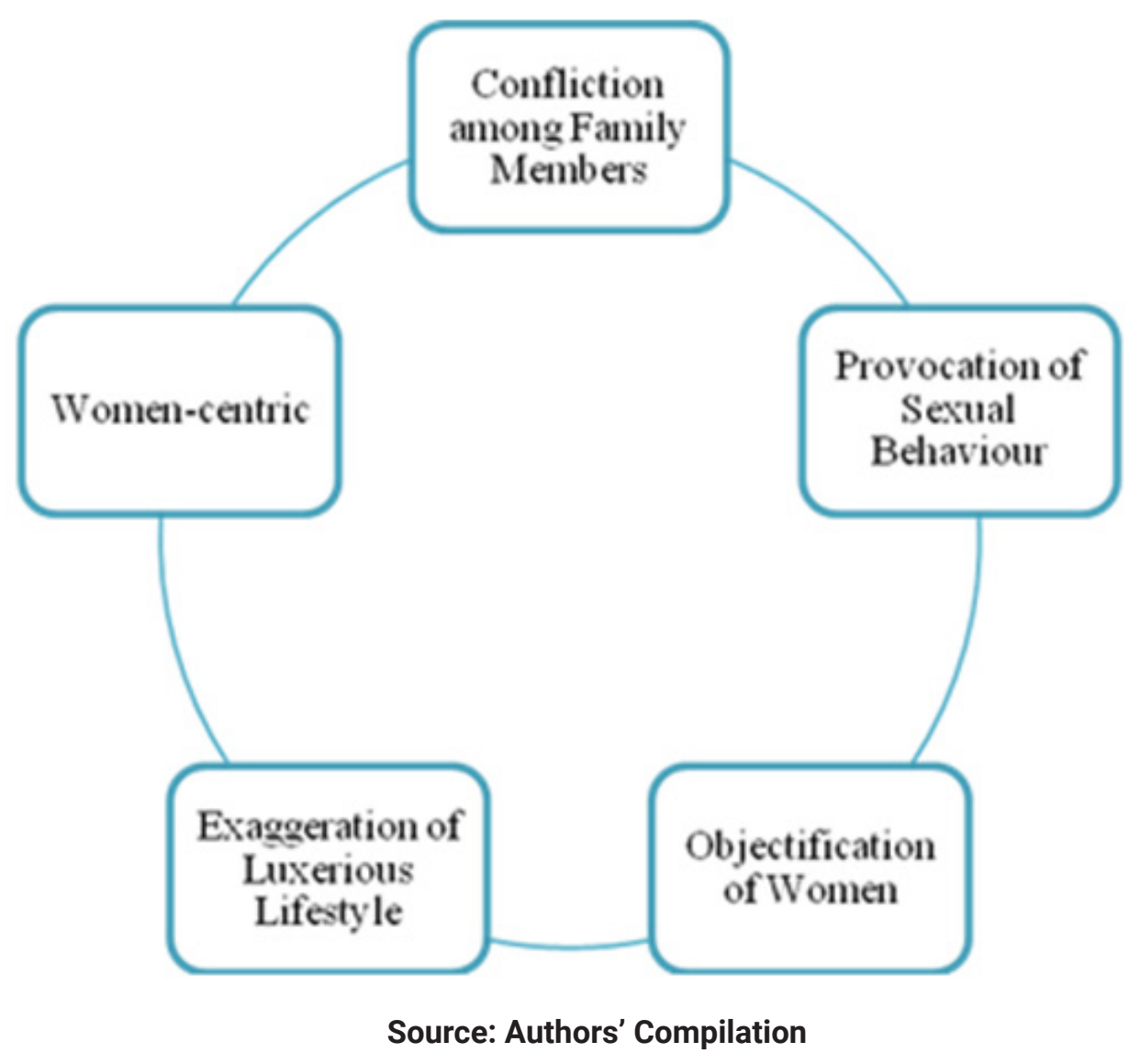

\section{Who Watches it and Why}

There are mainly two types of viewers of Indian TV serials i.e. Primary viewers and Secondary viewers. The primary viewers are mainly housewives and they follow the serials on a regular basis. They are highly enthusiastic about what is going on in each episode and analyze the plots and actors in a sophisticated way. Whereas, the secondary viewers are those who do not follow the serials regularly and are less reluctant about what is happening in the serials. The children, husbands and in-laws of the housewives are often the viewers of this type. Findings of this study show that watching of television serials if often linked with age and gender identities. From adolescence to older people, both male and female would watch these serials although housewives were the prime viewers of them. Indian drama serials are full of gorgeous jewelries, fashionable dresses 
and luxurious lifestyle that pull the audience significantly. Many of our respondents said that they watch these serials only for enjoying efficient acting of Indian actors that is barely seen in Bangladeshi programs. The programs in Bangladeshi TV channels lack this for budget and cultural issues. The participants also complained about too much advertising in the middle of programs and inconsistency in telecast. Lack of source of entertainment is another key reason of the women's inclination to it.

\section{Changes in Attitude and Lifestyle}

A large part of Bangladeshi viewers are inclined to watching Indian TV serials on a regular basis. Most of these viewers are women and the articulation on their forms of perception and knowledge essentially influence both family and social life. From socialization of children to family recreation, people now spend a huge time in front of the TV screen to watch these serials. We found that over $80 \%$ of the women were primary viewers of such serials and they got an acute addiction to it. We observed that many of the participants talked imaginary things as a result of their intense involvement in the serials. In some cases, they tried to correlate their practical life with the screened life. Such was the case with Mousumi Afroze, who is a regular viewer of Indian drama serials.

... when I saw the couple of my favorite serial got married eloping, it felt adventurous to me. I experienced an excitement and dreamed of such things in my life as well. I also want to arrange some rituals like sangeet, mehendi, haldi etc. as shown in the serials but unfortunately it did not happen because our family does not support this (Direct interview with Mousumi Afroze).

People spend a lot of time in front of the TV screen to watch what is being shown in the serials. They do not stop watching these for once but wait for the repeated telecast. They created such an acute addiction to serials that they cannot stay a single day without watching it. They prefer it more than their real life and sometimes forget about their duties. The viewers of these serials tend to follow the lifestyle portrayed in these serials and follow everything they learn from it. Not only do they dream of a life the characters are playing but also of their lifestyle. From ornaments to household utilities, these viewers impersonate everything they see. Farzana Habib, a mother-in-law of a regular viewer of Indian TV serials said about the reluctance of her daughter-in-law in family duty in this regard.

My daughter-in-law wastes a huge amount of time watching TV serials. Most often she does not pay attention to household works. She has no care for her child's education even at the time of their exams (Direct interview with Farzana Habib).

It is apparent that the makers of these serials create a web of illusion and the women fall into it. The illusion is that they finish one episode by putting some twists and mysteries and women become curious of it and this inquisitiveness keeps them busy all day long that is why they cannot concentrate on their household chores. Some of the participants in FGDs and case studies stated that they are addicted to it and they could skip a meal but not their favorite Hindi TV serials. It is worth mentioning that the viewers are being psychologically manipulated by most of the TV serials and they sometimes do not know that this fascination is designed by the media people just for commercial purpose.

\section{Changes in Family and intimate relationship}

We observed that watching Indian TV serials had significant effect on family and interpersonal relationship. In this study, the viewers of these programs in most of the families were more than one person. Often they reported watching the programs harmoniously, although sometimes problems between the husband and wife were created because of differences in preferences. For example, the husband wanted to watch sports or news but the wife wished to enjoy serials at that time. As a result, there occurred a conflict - albeit not always apparent -between them. One of our participant in KII whose 
wife is a regular viewer of TV serials, shared his experience over relishing TV programs.

Almost every day we fight against each other for a silly matter-which channel to be watched. Especially, when I want to watch an important cricket match of Bangladesh or a live talk show, she persists to watch Indian serials and sprawls for the TV remote from me. Even there were occasions when TV remotes are broken over such issues (Direct interview with Mehedi Shakil).

A further salient family turmoil happens because of the impact of the aforesaid daily TV soaps. As the serials show disbelief among the family members, suspicion between husband and wife and other illegal issues which are devoid of ethics. Many of the participants believed that one may learn things like extra-marital relationship and suspicion among family members and may apply these to family life.

People regularly watch conflicts and clashes among family members in many of these TV serials. These events are, to a certain extent, reflected in the viewers' practical life. Nowadays, a clash between in-law relations has become very common and family bonding is deteriorating day by day. Many of the participants in FGDs and KIIs reported how these TV series are creating an intense disbelief among family members. The main viewers-female members of a family- mentioned the positive aspects about these programs mostly. Interestingly many of them admitted that that these serials are increasing family and social bondage in some way. A female participant of the FGDs, shared her opinion in this regard.

...I think the concept of extended families is worsening at an alarming state at present. Many families are broken and the reciprocal relationship among the members is fading day by day. However, of course, there can be some exceptions, yet those exceptions cannot be an example (Direct interview with Mariam Begum).

\section{Art and culture}

Another main focus of this study is that the Indian TV serials are portraying an impractical image in front the viewers. They only show splendid, glazing and lustrous lives of the artists that attract the general spectators and they try to imitate these in their real life. Sandhya Rani, another participant, not only consults about the serials with her neighbors but also discusses about the dresses, ornaments, food habits and so on which are shown in these serials.

I like to lead a very stylish life like that of the TV stars. Wearing modern dress, matching jewelries, food habit, speaking approaches all I follow of them. Even I stay well dressed with make-up atthe home like the TV stars. I always try to buy things which I watch in serials and if I become unable to buy any product according to my choice, I become depressed. I think there is a secret competition among my neighbors about these things (Direct interview with Sandhya Rani).

Therefore, having been motivated by these concepts the women want through changes in their life. Interestingly, not only the women viewers but also the children are being badly affected by these drama serials. They are imitating foreign language (Hindi). Being very upset, Monika Debi, a mother-in-law of a viewer said about her grandchildren's degradation in behaviour and attitude.

My grandchildren have been becoming spoiled day by day in assistance of their mother. They also use Hindi language in conversation, replicate foreign lifestyle, food habit, late night party etc. (Direct interview with Monika Debi).

Another concerning issue is that in our marriage ceremonies we are blindly following foreign, of course Indian, rituals like sangeet, mehendi, haldi, sagai (engagement), after marriage reception and so on. As a result our native culture is falling at stake. Adopting foreign culture is a natural stimuli for people. As already mentioned, the social learning theory explicates that people learn from observing others' activities like habit, customs, practices, attitudes and behavior. To conclude this point, we argue that watch- 
ing and following the concepts of the TV series is the main reason of adopting an alien culture, and this is isolating us from our traditional Bangladeshi rituals.

\section{Risk factors}

These Indian serials are not only grabbing the native culture but also creating lots of other risks. Many believe that eve-teasing, rape, suicide and other antisocial activities are increasing day by day because of the prevalence these TV serials got. In addition, pre-marital and extra-marital relationship has become common and affecting the family and intimate relationships. By giving an example of a personal experience a male participant of KIls shared his opinion.

One of my cousins committed suicide because her husband made an extra-marital relationship with another woman. She was inspired from the Indian TV serials because both she and her husband were addicted to serials (Direct interview with Subhasis Mondal).

It is not like that these things did not exist in Bangladesh previously but these were somewhat less prevalent and people used to feel ashamed of revealing these in public. But nowadays the scenario has changed drastically. People do not feel shy in revealing these, they treat these like a trend or fashion, as these are being telecast openly on the TV screen. In various cases it has been seen that some too emotional girls and/or women have committed suicide just because of prohibition of watching these serials or of not getting their desired dress like those of the TV stars. However, there exists an interesting psychological issue regarding the intense attachment to these serials. In this respect, Dr. Saleha Mahmud, a psychiatrist shared some facts about the hormonal functions of human.

Dopamine and oxytocin are two types of hormones that erects from our brain. Dopamine, what it actually creates is 'want'. Dopamine causes us to seek, desire, and search. It is stimulated by unpredictability, by small bits of information, and by reward cues pretty much the exact conditions of media. If you tend to trust others, oxytocin will make you trust them more. Because of this reason viewers cannot resist themselves in watching those serials which create pleasure and attraction for them. On the other hand, if you carry around social anxiety and suspicion, oxytocin will amplify those feelings instead. For this reason sometimes these serials create suspicion into mind and originate family conflict and social anomalies (Direct interview with Dr. Saleha Mahmud).

Figure 2: Risk Factors Associated with Indian Drama Serials

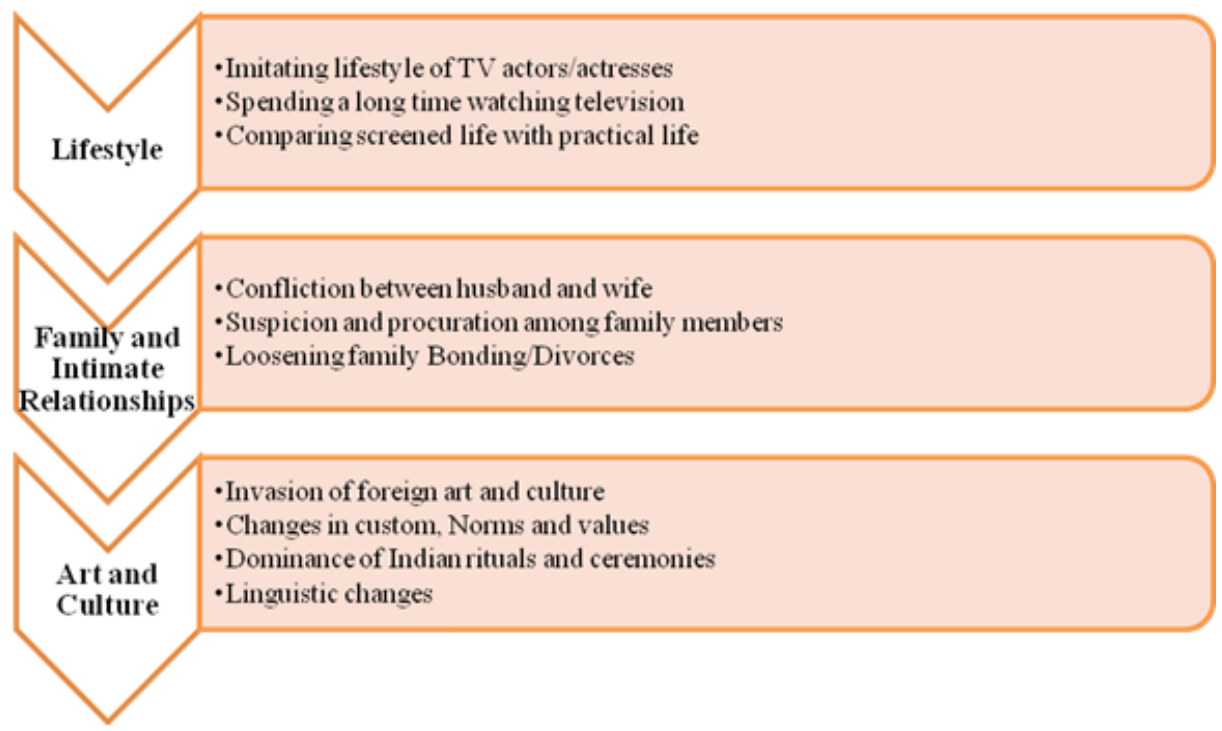

Source: Authors' Compilation 
The risk factors of Indian TV serials involve all three aspects of lifestyle, intimate relationships and culture of a society. Besides, these serials influence the political economy of Bangladesh these days as well. The newest fashions, language and enthusiasm for Indian culture has become highly trendy in Bangladesh at present. Although there is plenty of negative impacts that people talk about, experts point out some positive aspects too. People like Indian products, foods and even their language which has opened a plethora of possibilities to share and exchange between the two neighboring countries. The connection between India and Bangladesh is nowadays stronger more than ever and can be beneficial for both parties given the interest of both are served. However, political scientist suggest a careful dependency for a long term sustainable relationship as such dependency affects satellite countries most severely in the times of crisis.

\section{Discussion}

This paper attempts to explore the impact of Indian drama serial on Bangladeshi culture. Findings suggest that the impact is of different forms including how these drama serials are changing our lifestyle, how it affects our family and intimate relationships, how it influences our art and culture and what are the risk factors originated from the severe addiction of these programs. By analyzing literature such as journals, articles, theoretical background and most importantly the statement of the respondents and relevant people, we observed some significant implications from the present study.

This study identifies that the impact of Indian TV serial is primarily the result of globalization because globalization is the only source by which cultural imperialism (Tomlinson, 2003; Xue, 2008; Feigenbaum, 2001; Shah, 2016) and subjugation of foreign culture over the native one is very possible. Satellite channel is the creation of globalization and by the favor of the satellite channels we can easily share our art and culture with each other which is a positive sign but it also has some other effects. In the name of sharing culture, it is grabbing indigenous culture gradually and bounding people to adopt the non-native ones. Interestingly though, almost no Bangladeshi TV serials are telecast in India and therefore have not been able to do the similar by influencing Indian culture or society. The findings represent a similarity with what A. G. Frank (1966) called the dominance of metropolises over the satellite states.

According to cultivation theory, the more time people reside in the virtual world, the more they believe that social reality aligns with the reality portrayed on television (Riddle, 2009). The theory suggests that people can imitate and learn things from observation alone like observing others' attitude and behavior. It is evident that people are being socialized through television and it affects the public and their institutions (Morgan and Shanahan 2010; Gerbner et al. 1986). We also observed that participants in this study would acknowledge the on-screen practices as their own. Therefore, their lifestyle and family institution experiences undergo a dramatic change. Many would go crazy about this fairy as it affects their personal, family and socio-economic life above all. Besides, the social learning theory states that, children and adolescents from a social learning theory perspective, emphasizing imitative performance of vicariously reinforced consumption stimuli is also applicable in this context (Atkinson, 1976).

To identify why Bangladeshi people watch the Indian TV serials, we noted that there is a serious dearth of quality programs and also lack of talented and qualified artists, directors and producers in Bangladesh. And because of long advertising no program is enjoyable and it is often not up to the mark. On the other hand, the Indian serials are more enjoyable to watch because Indian serials are of better quality since they have bigger market, better quality artist and a greater production house that offers original contents. Many believe that Indian TV serials drama serials are life oriented because they present the ups and downs of life in a more vivid way that those of Bangladeshi TV channels. Besides, many would complain that there are more commercials and telecast timing issues in Bangladeshi TV serials which made them prefer the Indian TV serials. 
Whatever the reasons behind watching Indian TV serials are, some concerns about getting addicted to it is arising. We observed that the viewers are adopting the story of the serials in their practical life and they started comparing their life with it. As a result, their lifestyle is being changed, although gradually, but significantly. They view these programs as a way of getting separated from their boring day-to-day schedule and wish their life would be as gorgeous as the characters on the screen. This can be confounded with the social cognitive theory that explains human psychosocial functioning of reciprocal causation. This theory accords a central role to cognitive, vicarious, self-regulatory, and self-reflective processes. Through symbols, people give meaning, form, and continuity to their experiences. The psychology of the blind viewers works according to this theory (Bandura, 1986). They watch the symbols and images of crime and anti-social activities; try to give these a meaning and continue in their personal experience.

Most of the women in Bangladesh are housewives and they are the majority who watches the Indian TV serials on a regular basis. They watch these programs not only once but the repeat telecasts also and that has created an obsession among them. This compulsion sometimes becomes so acute that their husbands and in-law relatives often complain about their indifference to family and children. Existing literature also suggests that watching television significantly influences women and their lifestyle in many ways (Ali et al., 2014). Our findings suggest that following Indian lifestyle, viewers of Bangladesh are replicating their language, food, attitude, behaviour, dress code and so on significantly. People use Hindi words during conversation and traditional rituals of Bangladesh are also being influenced. In marriage ceremonies, Indian customs like sangeet, mehendi, sagai, haldi etc. have taken over the native customs and rituals. Such experience can be explained with the term cultural assimilation where a person or a group's language and/or culture come to resemble those of another group.

Some risk factors like crime, eve-teasing, rape, pre-marital sexual relationship, extra-marital relation, vulgarism etc. can originate due to the prevalence of Indian TV serials. Sometimes, the serials are regarded as s source of social disorganization instead of a source of entertainment (Helal, 2014). As these drama serials show elements of family politics, eve-teasing, rape and other things, this may contribute to the ever increasing rate of crime in society. Many reported that these serials are addictive. Such addiction results in disturbances for leading a normal life which many of the respondents found difficult. Often the situation reaches such a stage where the audience does not feel for their own life as much as they feel for the screen. Sometimes, there are reports of suicide when faced prohibition for watching the serials.

\section{Conclusion}

The most popular programs nowadays in Bangladesh are Indian serials. The day to day activities and lifestyle of the people in Bangladesh largely shows the reflection of it. This study on two major cities of Bangladesh finds out that Bangladeshi cable operators telecast a number of Indian TV serials which influence the family, intimate relationships, art, language and traditions of indigenous culture. The norms, values, socialization pattern, family, marriage, education, social interaction all are changing as a result. This cultural imperialism is not only affecting our social life but also affects our psychology as people are getting addicted to these TV serials. The effect of Indian TV serials goes further beyond socio-psychological to political economic consequences as they affect the market system and commercial purposes. This study makes a simple attempt to address these issues based on perceptions of participants as we acknowledge that there is the need of more and more study about this topic to create consciousness among the people. It is good to be introduced to different cultures but it needs monitoring where necessary if indigenous culture is threatened. 


\section{References}

ALI, A., KHALID, A., \& HASSAN, S. A. (2014). The Impact of Indian Dramas on Language and Dressing of Females. IOSR Journal Of Humanities And Social Science (IOSR-JHSS), 19(1), 66-71.

ALI, A., KHALID, A., \& HASSAN, S. A. (2015). The Impact of Indian Dramas on Language and Dressing of Females. Online Journal of Communication and Media Technologies, 5(1), 159-171.

ALI, A., NAWAZ, A. \& HASSAN, S. A. (2014). Impact of Cable/T.V on Modern Lifestyle: A Study of Women. Research on Humanities and Social Sciences. 4(13): 85-92.

BANDURA, A., Social foundations of thought and action : a social cognitive theory. 1986, Englewood Cliffs, N.J.: Prentice-Hall.

CAREY, S. 1993. Mass Media Violence and Aggressive Behavior. Criminal Justice Matters. 11 (1): 8-9.

CHARLES K. ATKIN (1976),"Children's Social Learning From Television Advertising: Research Evidence on Observational Modeling of Product Consumption", in NA - Advances in Consumer Research Volume 03, eds. Beverlee B. Anderson, Cincinnati, OH : Association for Consumer Research, Pages: 513-519.

FEIGENBAUM, H. B. (2001). Globalization And Cultural Diplomacy. USA: Center for Arts and Culture.

FRANK, A. G. (1966). The Development of Underdevelopment. USA: New England Free Press.

GERBNER, G.; GROSS, L.; MORGAN, M. \& SIGNORIELLI, N. (1986). "Living with television: The dynamics of the cultivation process". In J. Bryant \& D. Zillman. Perspectives on media effects. Hilldale, NJ: Lawrence Erlbaum Associates. pp. 17-40.

HELAL, M. A. (2014). Impacts of Indian Drama Serials on Bangladeshi Social System: An Overview of People's Perception. ASA University Review, 8(1), 242-249.

HUESMANN, L. R. (2007). The Impact of Electronic Media Violence: Scientific Theory and Research. The Journal of Adolescent Health : Official Publication of the Society for Adolescent Medicine, 41(6 Suppl 1), S6-13.

ISLAM, A. (2013). Hindigenization of Bangladeshi Culture through the Penetration of Satellite TV: Paradigm of Modernization vs. Dependency Theory. New Media and Mass Communication, 18, 15.

JUNI, M. M., SADIQ, F., KAREEM, J., ALAM, M. K., HAIDER, I., ASHRAF, C. A., \& ALI, M. M. (2014). The Influence of Indian Culture on Pakistani Society:A Case Study of Layyah City. International Journal of Innovation and Applied Studies, 8(3), 1120-1124.

KHANAM, D., SARWAR, M. M., \& ABIR, T. M. (2014). 'Broadcasting Indian TV Serials In Bangladesh: The Beginning of the Social Change': A Study on Present Situation of Bangladesh. IOSR Journal Of Humanities And Social Science (IOSR-JHSS), 19(7), 142-147.

MORGAN, M.; SHANAHAN, J. (2010). "The State of Cultivation". Journal of Broadcasting \& Electronic Media. 54 (2): 337-355.

NASEER, M., MANJ, D. Y., RIAZ, D. F., AWAN, D. K., SIDDIQUE, A., SHAHZADI, S., . . AHMED, Z. (2014). Exposure to foreign media and changing in cultural traits- A Study Conducted In District Sargodha and Multan. Scholars Journal of Arts, Humanities and Social Sciences, 2(4B), 563.

PALINKAS, L. A., HORWITZ, S. M., GREEN, C. A., WISDOM, J. P., DUAN, N., \& HOAGWOOD, K. (2015). Purposeful sampling for qualitative data collection and analysis in mixed method implementation research. Administration and Policy in Mental Health, 42(5), 533-544.

QAMAR, M., ASIM, M., SHAWAR, D. -E., \& ZAFAR, M. I. (2012). The Impacts Assessment of Indian Culture on Pakistani Society In Faisalabad. International Journal of Research in Social Sciences And Humanities, 1(5), 53-55.

RIDDLE, K. (2009). Cultivation Theory Revisited: The Impact of Childhood Television Viewing Levels on Social Reality Beliefs and Construct Accessibility in Adulthood (Conference Papers). International Communication Association. pp. 1-29.

RUWANDEEPA, V. D. (2011) "Impact of Indian Tele-dramas on Women's Behaviour in Sri Lanka" International Journal of Communicology, 1(1), 31-40.

SALAM, U. (2013). The Telly Effect. Retrieved August 7, 2017, from The Daily Star: http://www.thedailystar.net/ news/the-telly-effect.

SHAH, A. A., NAZIR, F., BHATTI, M. B., \& GILLANI, A. (2016). Cultural Effects of Indian Primetime Dramas on Female Youth of Peshawar (Pakistan). Sci.Int.(Lahore), 28(5), 29.

SHAMSHER, R., \& ABDULLAH, M. N. (2012). Effect of Satellite Television on the Culture of Bangladesh: The Viewers Perception . European Journal of Business and Management, 4(9), 45.

TOMLINSON, J. (2003). Globalization and Cultural Identity [Chapter 23 from: The global transformations read- 
er: an introduction to the globalization debate]. In A. G. McGrew, \& D. Held, The global transformations reader: an introduction to the globalization debate (2nd ed., pp. 269-277). Cambridge, U.K., Malden, MA: Distributed in the USA by Blackwell Pub, Polity Press in association with Blackwell Pub.

XUE, C. (2008). A Review of Tomlinson's Views on Cultural Globalization. Asian Social Science, 4(6), 112.

YOUSAF, Z., ARSHAD, \& AMMARAH. (2014). Impact of Indian Dramas on Interaction behavior of female. IOSR Journal Of Humanities And Social Science (IOSR-JHSS), 19(4), 89. 